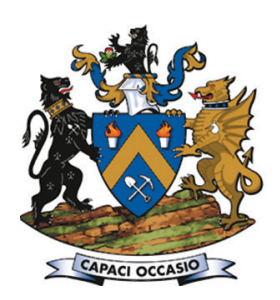

Affiliation:

1 Pyrometallurgy Division, Mintek, South Afric.

${ }^{2}$ SINTEF Industry, Trondheim,

Norway.

${ }^{3}$ Aeronautic Systems, CSIR,

South Africa

Correspondence to:

Q.G. Reynolds

Email:

quinnr@mintek.co.za

Dates:

Received: 15 Mar. 2019

Revised: 13 May 2019

Accepted: 25 May 2019

Published: June 2019

How to cite:

Reynolds, Q.G., Olsen, J.E.,

Erwee, M.W., and. Oxtoby, O.F

Phase effects in tap-hole flow - a computational modelling study.

The Southern African Insitute of Mining and Metallurgy

DOI ID:

http://dx.doi.org/10.17159/24119717/671/2019

ORCiD ID:

Q.G. Reynolds

https://orchid.org/0000-0002-

5196-8586

This paper was first presented at the Furnace Tapping 2018

Conference, 15-16 October

2018, Nombolo Mdhluli

Conference Centre, Kruger

National Park, South Africa.

\title{
Phase effects in tap-hole flow - a computational modelling study
}

\author{
Q.G. Reynolds ${ }^{1}$, J.E. Olsen ${ }^{2}$, M.W. Erwee ${ }^{1}$, and O.F. Oxtoby ${ }^{3}$
}

\begin{abstract}
Synopsis
The extraction of molten products and wastes through smelting furnace tap-holes during the tapping process is a complex procedure involving many coupled thermophysical effects. Insight into the fluid flow behaviour in such systems can be gained by using computational mechanics tools to build highfidelity models of the fluid flow and other relevant physics. Previous work using such models indicates that the nature of the flow in the tap-hole, as well as operational parameters such as the tapping flow rate, depends strongly on the properties of the material being tapped and the geometry of the tap-hole channel. Additional complications arise when multiple fluid phases (for example, slag and metal) are present simultaneously, when porous coke beds hinder flow to the tap-hole entrance, and when the geometry of the tap-hole changes over time due to cycles of wear and repair. In the present work, challenges with the coupling of phenomena such as multiphase flow and porosity into computational fluid dynamics methods for tap-hole modelling are discussed in the context of electric furnaces used for ferromanganese production. Qualitative and quantitative results of computational models of flow through tap-holes are presented and compared as a function of material parameters to determine sensitivity effects, and in response to operational parameters to determine typical process behaviour over the duration of a tap.
\end{abstract}

\section{Keywords}

fluid flow, multiphase, modelling, tap-hole, ferromanganese.

\section{Introduction}

Pyrometallurgical production using electric furnaces accounts for substantial portion of the world supply of ferroalloys and other strategic materials (Degel et al., 2015). A range of different furnace designs may be used depending on the metallurgical process, with circular three-electrode submerged arc furnaces (SAFs) powered by alternating current being the most common for commodities such as ferromanganese and silicomanganese (Olsen, Tangstad, and Lindstad, 2007).

As shown in Figure 1, manganese furnaces typically operate with a deep charge consisting of an upper layer of loose burden (onto the upper surface of which is fed solid raw material), a molten slag layer partially or completely filled with unreacted carbonaceous reductant (generally metallurgical coke), and a molten metal layer which settles to the bottom of the furnace due to its high density. The solid particles present in the slag and burden layers form porous beds which hinder the fluid flow of molten process material and gases inside the furnace (Olsen, Tangstad, and Lindstad, 2007).

In order to remove material from the furnace during normal operations, a single tap-hole is built into the sidewall of the vessel near to the level of the hearth. Tapping involves removing both slag and metal phases through the same tap-hole channel, which makes tap-hole design, operation, and maintenance particularly complex. In the case of processes such as ferromanganese, which operate with no external gas injection or open arcs present at the furnace electrodes, flow of material out of the tap-hole is driven primarily by the hydrostatic pressure generated by the weight of the solid and liquid phases above the tap-hole.

Measurement of experimental data from the interior of furnace tap-holes during operation is extremely challenging for a number of reasons, including the high temperatures of the materials involved, physical access limitations, and hazardous environment (see Figure 2). Computational models of tapping can provide useful additional insight in such cases.

Full models of manganese smelting furnaces which include the tap-hole region have been produced by several authors, notably Kadkhodabeigi, Tveit, and Johansen (2011) who studied in some detail the effect of furnace conditions on metal, slag, and gas flow from the tap-holes of silicomanganese furnaces 


\section{Phase effects in tap-hole flow - a computational modelling study}

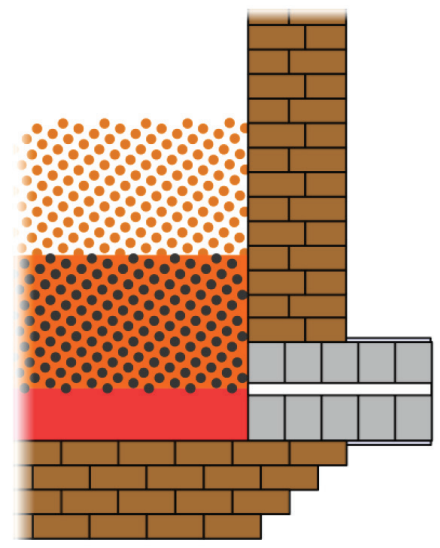

Figure 1-Schematic diagram of the tap-hole region in a ferromanganese furnace showing metal, coke/slag, and burden layers
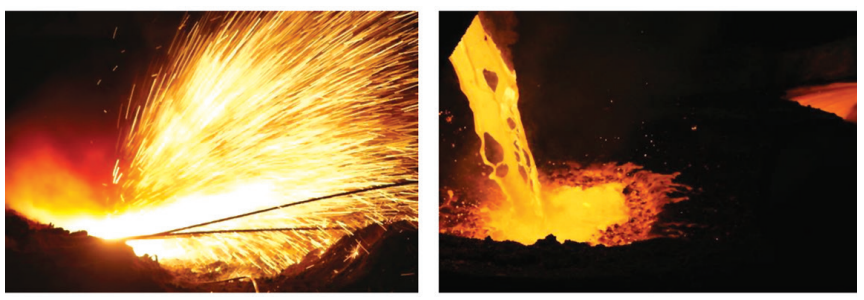

Figure 2-(I) Lancing a submerged arc furnace tap-hole (image"“Flying Sparks' $\odot$ Joalet Steenkamp 2016), (r) tapping stream detail on a silicomanganese furnace (image 'Follow Me' $\odot$ Joalet Steenkamp 2013)

and demonstrated important connections between fluctuations in the furnace interior pressure and tapping flow rates. More detailed models of the tap-hole entry and channel regions are also used in furnace design (Muller, Zietsman and Pistorius, 015) but often focus preferentially on heat transfer effects through the surrounding refractories since these are key factors in optimizing the engineering design of the tap-hole structure.

Although it is a secondary problem in the thermal design, the fluid flow behaviour in furnace tap-hole entry regions and channels is nonetheless interesting and does impact operational aspects such as tap-hole refractory wear, tapping flow rates, and (in the case of single tap-hole furnaces) phase intermixing. As a result, further study of tap-holes from a fluid flow perspective alone was thought to be of some merit. Velocity and qualitative characteristics of the flow inside the tap-hole channel are functions of the furnace operating conditions, the geometry of the tap-hole, and the physical properties of the process materials. This was previously studied for the case of a generalized tap-hole carrying a single fluid phase (Reynolds and Erwee, 2017), and is extended with the present work to include the presence of porous media as well as multiphase fluid flow in the context of tapping from ferromanganese furnaces.

\section{Model description}

\section{Governing equations}

Fluid dynamics in furnace tap-holes is governed by the fundamental laws of conservation of momentum and mass, the Navier-Stokes and continuity equations. These nonlinear partial differential equations must be extended with terms to account for multiphase flow effects and drag forces that act on the flow field in porous media, giving the result shown in Equations [1]-[3] for two-phase flow.

$$
\begin{aligned}
& \frac{\partial}{\partial t}(\phi \rho \vec{u})+\nabla \cdot(\phi \rho \vec{u} \vec{u})=\nabla \cdot \phi \mu \nabla \vec{u}+ \\
& \phi\left(\overrightarrow{F_{P}}+\rho \vec{g}-\gamma \nabla \cdot\left(\frac{\nabla \alpha}{|\nabla \alpha|}\right) \nabla \alpha-\nabla P\right) \\
& \nabla \cdot(\phi \vec{u})=0 \\
& \frac{\partial}{\partial t}(\phi \alpha)=\nabla \cdot(\phi \alpha \vec{u})
\end{aligned}
$$

In these equations, $\phi$ is the porosity field, $\rho$ is the density field, $\vec{u}$ is the velocity vector field, $P$ is the pressure field, $\mu$ is the viscosity field, $\gamma$ is the interfacial surface tension between the two phases, $\alpha$ is the phase fraction field indicating the volume fraction of slag phase, $\overrightarrow{F_{P}}$ is the drag force acting on the fluid due to the porosity field, and $\vec{g}$ is the vector of acceleration due to gravity. All field parameters are able to vary in both space and time.

The equations must be closed with an appropriate expression for the porous flow drag force. The Ergun equation, a well-known and extensively validated correlation developed for flow in fixed and fluidized beds, was used in this case (Equation [4]).

$$
\overrightarrow{F_{P}}=\left(\frac{150 \mu(1-\phi)^{2}}{d_{c}^{2} \phi^{3}}+\frac{1.75 \rho(1-\phi)|\vec{u}|}{d_{c} \phi^{3}}\right) \vec{u}
$$

Here the viscosities and densities refer to the fluid phase, and $d_{c}$ is the diameter of the particles making up the porous bed.

\section{Software implementation}

Solutions to Equations [1]-[4] were obtained using a finite volume method solver developed for the OpenFOAM ${ }^{\circledR}$ open source computational mechanics platform, version 5.0 (OpenFOAM, 2018). To account for phase dynamics the volume of fluid (VOF) method, in which a single velocity and pressure field describes both fluid phases present, was used. Velocity and pressure fields were solved at each time step using the PIMPLE algorithm, which unifies the PISO (pressure-implicit with splitting of operators) and SIMPLE (semi-implicit method for pressure-linked equations) approaches. Careful treatment of the porosity terms is necessary in order to retain numerical stability and accuracy near discontinuities, and is discussed at length in Oxtoby, Heyns, and Suliman (2013). Additional capability enabling the porosity field to follow only one of the fluid phases as the solution evolves in time was also implemented.

Computational meshes for the models were generated using two different tools for the purposes of cross-comparison; ANSYS DesignModeler (ANSYS, 2018) and cfMesh (cfMesh, 2018).

Models were executed in parallel on between 16 and 64 CPU cores using the CentOS Linux-based Lengau cluster at the Centre for High Performance Computing (CHPC 2018). Execution times ranged from two hours up to a day, depending on model resolution and parameters.

\section{Model geometry and boundary conditions}

In order to study the problem of fluid flow during ferromanganese tapping, a simple model geometry was developed consisting of a large plenum area representing the interior of the furnace and a cylindrical channel representing the tap-hole. Realistic dimensions typical of ferromanganese furnaces were used, and are reported later. The model geometry is shown schematically in Figure 3. 


\section{Phase effects in tap-hole flow - a computational modelling study}

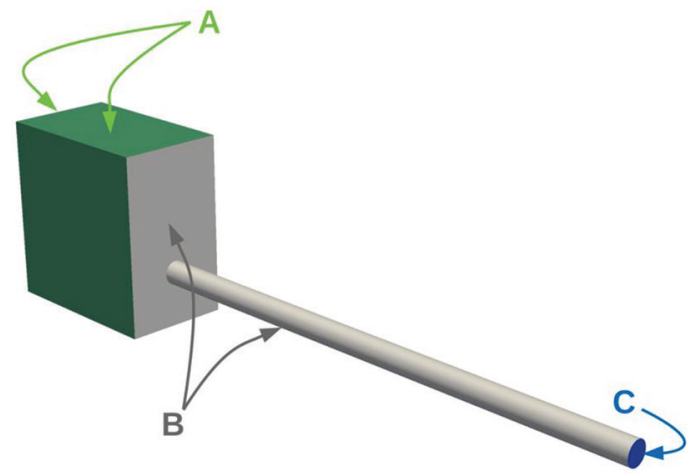

Figure 3-Geometry of model region showing boundary locations

Boundaries ' $\mathrm{A}$ ' are treated as free inlet-outlet surfaces through which fluids can pass, and are taken to represent the farfield conditions in the furnace away from the tap-hole entrance area. $P$ is fixed at the hydrostatic head values, $\vec{u}$ is calculated from the local pressure gradient, and $\alpha$ is set to fixed values representing the bulk level of the slag-metal interface far from the tap-hole. Boundaries 'B' are treated as solid walls, with a no-slip boundary condition applied for $\vec{u}$ and a fixed flux pressure (fixed hydrostatic gradient) condition for $P$. A zero-gradient boundary condition is also applied for the $\alpha$ field. Boundary ' $C$ ' is the taphole outlet at which $P$ is set to atmospheric pressure, $\vec{u}$ is again calculated from the local pressure gradient, and a zero-gradient boundary condition is applied to $\alpha$.

All models were initialized at stagnant conditions with the level of the slag-metal interface equal to that in the bulk interior of the furnace.

\section{Model post-processing}

In order to extract useful data outputs from the model, the results were processed at run time to obtain the values of slag mass flow rate $\dot{m}_{s}$, metal mass flow rate $\dot{m}_{m}$, and interface deformation $\delta_{i}$ as a function of time. The flow rates are obtained by simple integration on the computational mesh at the outlet, as shown in Equation [5].

$$
\begin{aligned}
& \dot{m}_{s}=\sum_{n, \text { outlet }} \rho_{s} \alpha_{n}\left(\vec{A}_{n} \cdot \vec{u}_{n}\right) \\
& \dot{m}_{m}=\sum_{n, \text { outlet }} \rho_{m}\left(1-\alpha_{n}\right)\left(\vec{A}_{n} \cdot \vec{u}_{n}\right)
\end{aligned}
$$

Here $\vec{A}$ is a vector directed normal to the surface of the mesh elements at the outlet boundary and with magnitude equal to their area, subscript $n$ indicates values at a specific element in the surface mesh, and subscripts $m$ and $s$ refer to the metal and slag phases respectively.

Calculation of the deformation of the interface is somewhat more difficult. At each time step, a small section of the mesh at the end of the tap-hole near to the outlet is first selected. The volume fraction of metal as well as the surface area of the slagmetal interface in this section is then calculated by integration in an analogous fashion to the method used for the flow rates. The equivalent surface area of the slag-metal interface under quiescent conditions is then calculated using the volume of the metal, and $\delta_{i}$ as a dimensionless measure of the deformation of the interface is obtained by dividing the actual surface area by the equivalent quiescent area. The concept is illustrated graphically in Figure 4.

In addition to the quantitative information obtained, qualitative visualizations of the flow and phase fields were generated using the raw output from OpenFOAM ${ }^{\circledR}$ in ParaView, an open source visualisztion application (ParaView 2018).

\section{Model parameter estimation}

Material properties and operating conditions are required as inputs to the computational models. In order to estimate material properties, their chemical compositions are required. A standard high-carbon ferromanganese product specification (Letsoalo and Steenkamp, 2017) was used for the metal, and a range of compositions from industrial operations as shown in Table I was used for the slag (Olsen, Tangstad, and Lindstad, 2007). Densities were estimated from molar volumes (Mills, 2011) and viscosities were calculated using structural methods available in the FactSage thermochemical software package (Bale et al., 2016; Tang and Tangstad, 2007).

Coke particle sizes in the coke-slag bed in the vicinity of the tap-hole away from the central reaction zones under the electrodes were estimated from furnace dig-out photographs and previously published information to be under $20 \mathrm{~mm}$ (Barcza et al., 1979). The coke bed in this region is assumed to be very loosely packed, as it forms by gradual accumulation of coke particles at the periphery of the furnace by slow convection in the slag. For loose beds of irregular particles, packing porosities from 0.35 to 0.7 are possible (Yu, Zou, and Standish, 1996).

In order to obtain an estimate of the internal hydrostatic pressure in the vicinity of the tap-hole, measures of the height of the burden layer, slag and coke bed, and metal phase above the tap-hole centreline were required. These were obtained from a combination of discussion with researchers working in the industry and previously published results (Barcza et al., 1979; Olsen, Tangstad, and Lindstad, 2007). The ranges used in the calculations are shown in Table II.

Calculating the hydrostatic pressures from these values gives values between 50 and $90 \mathrm{kPa}$. Such a large range occurs primarily as a result of the significant variations in burden, slag
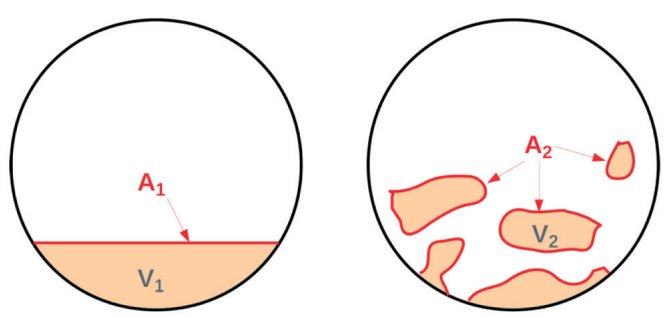

Figure 4-Diagram showing calculation of interface deformation, $\delta_{i}=\mathbf{A}_{2} / \mathbf{A}_{1}$ for $V_{1}=V_{2}$

\section{Table I}

Typical slag compositions for HCFeMn production

\begin{tabular}{|l|c|c|} 
Slag component & Mass \% (min.) & Mass \% (max.) \\
\hline $\mathrm{SiO}_{2}$ & 23.1 & 30.0 \\
$\mathrm{Al}_{2} \mathrm{O}_{3}$ & 4.3 & 20.7 \\
$\mathrm{CaO}$ & 16.9 & 34.4 \\
$\mathrm{MgO}$ & 4.0 & 6.6 \\
$\mathrm{MnO}$ & 15.1 & 40.9 \\
\hline
\end{tabular}




\section{Phase effects in tap-hole flow - a computational modelling study}

Table II
Furnace charge properties used to determine
hydrostatic pressure for tapping
\begin{tabular}{|l|c|c|c|}
\hline Phase or layer in furnace & Height & Density & Porosity \\
\hline Burden & $2.3-2.5 \mathrm{~m}$ & $3000 \mathrm{~kg} / \mathrm{m}^{3}$ & 0.4 \\
Slag & $1.0-1.8 \mathrm{~m}$ & $3000 \mathrm{~kg} / \mathrm{m}^{3}$ & 0.5 \\
Coke Bed & $1.0-1.8 \mathrm{~m}$ & $1500 \mathrm{~kg} / \mathrm{m}^{3}$ & 0.5 \\
Metal & $0-0.25 \mathrm{~m}$ & $7500 \mathrm{~kg} / \mathrm{m}^{3}$ & 0 \\
\hline
\end{tabular}

and coke, and metal heights that are possible between different furnaces and operating regimes. It is also important to note that this assumes that the burden layer is fully supported by the buoyancy of coke particles immersed in the slag (and possibly metal) layer, which is open to some debate.

\section{Results and discussion}

The operating conditions and material properties selected for the ferromanganese furnace tap-hole model are shown in Table III. The behaviour and numerical error of the model was initially studied for this base case set of parameters, followed by changes in individual values to identify sensitivity and operationalvariable responses.

Here, $\Delta P$ is the hydrostatic head pressure applied as a boundary condition in the model, $h_{i}$ is the position of the interface in the main furnace volume relative to the tap-hole centreline, $D$ is the tap-hole diameter, $L$ is its length, and $h_{t}$ is the height of the centreline of the tapping channel above the furnace hearth.

Each model was run for 3 seconds simulation time, with data being gathered and analysed over the last 0.5 seconds after the initial conditions had decayed and the flow was fully established. The coke bed was set to track the slag phase only, and was limited in extent to the plenum region outside the tap-hole channel.

\section{Numerical testing and validation comments}

Validation of computational models of single- and multiphase fluid flow in the presence of porous media has been addressed to a large degree in pre-existing work (Kadkhodabeigi, Tveit, and Johansen, 2011; Reynolds and Erwee, 2017; Oxtoby, Heyns, and Suliman, 2013), and the reader is referred to those publications for details. As the present work is primarily exploratory in nature, direct validation of the tap-hole model against measured data from ferromanganese furnaces is left to future work.

It is, however, important to appreciate that complex nonlinear multiphysics models such as those used here can exhibit many undesirable dependencies on their numerical implementation; this is clarified for the ferromanganese tap-hole model in the following sections.

\section{Effect of model resolution}

In order to determine the mesh dependence of the model, meshes were generated at a number of different resolutions with characteristic element sizes in the tap-hole channel from $0.0025 \mathrm{~m}$ (239 066 elements) to $0.00125 \mathrm{~m}$ (1 841291 elements). Results from the lowest and highest resolution cases are compared in Figures 5 and 6.

It is clear that while the predicted flow rates of slag and metal are similar on both small and large meshes, the interface deformation shows considerable dependence on the model resolution. The reason for this can be seen more clearly in Figure 6, which shows that the slag-metal interface breaks up considerably due to a highly three-dimensional swirling flow that develops as the metal enters the tap-hole underneath the more viscous, coke-filled slag layer. In VOF models, the minimum size of the entrained droplets of one phase in another is limited by size of the mesh elements; as the resolution is improved, more small droplets can be resolved and the calculated interface deformation increases. A summary of the mesh dependence results is shown in Figure 7.

\section{Table III}

Base case parameters for ferromanganese furnace tap hole model

\begin{tabular}{|l|c|c|c|}
\hline Parameter & Value & Parameter & Value \\
\hline$\mu_{s}$ & $0.1 \mathrm{~Pa} . \mathrm{s}$ & $d_{c}$ & $0.01 \mathrm{~m}$ \\
$\rho_{s}$ & $3000 \mathrm{~kg} / \mathrm{m}^{3}$ & $\Delta P$ & $70 \mathrm{kPa}$ \\
$\mu_{m}$ & $0.005 \mathrm{Pa.s}$ & $h_{i}$ & $0 \mathrm{~m}$ \\
$\rho_{m}$ & $7500 \mathrm{~kg} / \mathrm{m}^{3}$ & $D$ & $0.065 \mathrm{~m}$ \\
$\gamma$ & $0.5 \mathrm{~N} / \mathrm{m}$ & $L$ & $1.5 \mathrm{~m}$ \\
$\phi$ & 0.5 & $h_{t}$ & $0.15 \mathrm{~m}$ \\
\hline
\end{tabular}
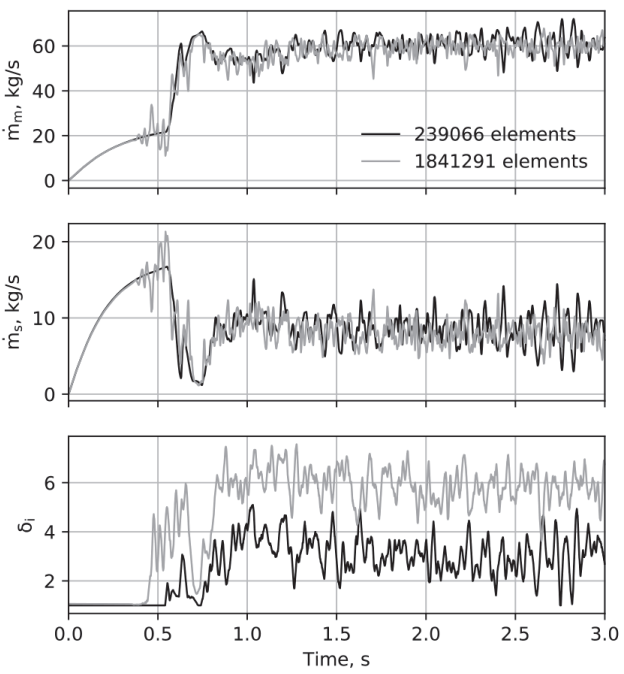

Figure 5-Evolution of slag and metal flow rates and interface deformation $\delta_{i}$ (see Figure 4) over time, comparison of mesh resolutions

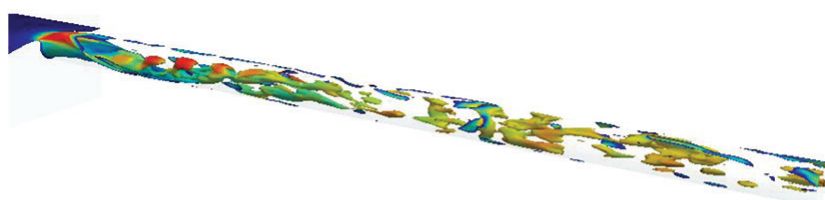

(a)

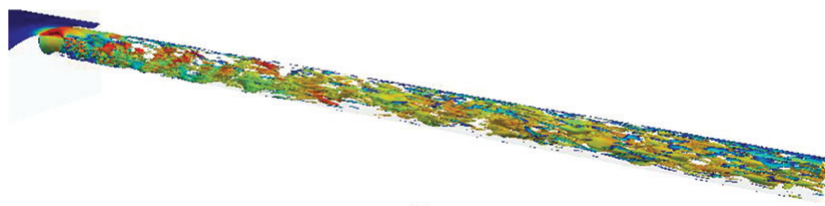

(b)

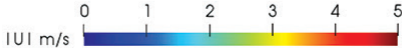

Figure 6-Slag-metal interface surface at end of simulation coloured by local fluid velocity, (a) low-resolution model, (b) high-resolution model 


\section{Phase effects in tap-hole flow - a computational modelling study}
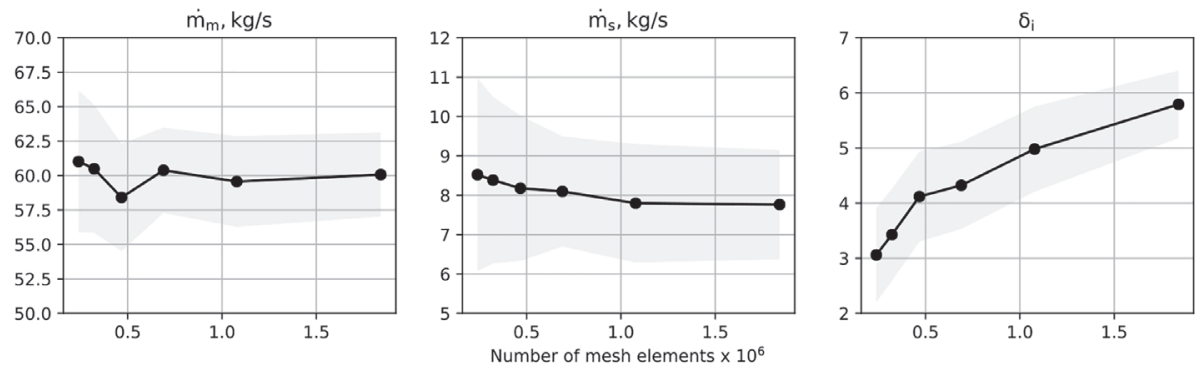

Figure 7-Changes in calculated variables with mesh size (solid line shows average for last 500 ms of model data, shaded region shows standard deviation)

These results bear out the initial assessment that while the slag and metal flow rate behaviour is captured fairly consistently across a wide range of resolutions, the interface deformation continues to demonstrate appreciable mesh dependence up to the finest resolutions tested. This has implications for how such models are used - if the intention is to study interface effects in great detail, significantly larger meshes than those employed here will likely be necessary.

\section{Effect of meshing algorithms}

The numerical characteristics of the model were investigated further using different software tools to generate the computational meshes used. Identical geometries were meshed using DesignModeler and cfMesh software at comparable linear element sizes and distributions, and exported for solution using the same OpenFOAM ${ }^{\circledR}$ solver in both cases. Although the meshes are constrained to produce elements of the same size in the plenum and tapping channel regions, the algorithms used in each tool differ to some degree and this results in slightly different mesh element arrangements and local refinements. This can be seen in Figure 8. Optimal meshing of geometries, particularly for hexahedral mesh elements, is tremendously complex and is still an open problem in the pre-processing of models for computational engineering; very few fully-automated methods exist for this task, hence the range of possible mesh topologies obtained from different tools.

Models were run on meshes generated by both tools at tapping channel mesh element sizes of $0.0025 \mathrm{~m}$ and $0.00125 \mathrm{~m}$. The results are shown in Figure 9.

It is interesting to observe that at low resolutions, the time averages and dynamics in the results from both tools appear to match well for all output variables. However, at higher
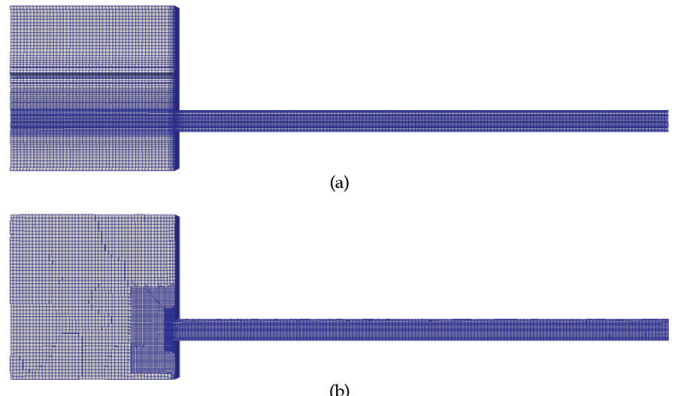

(b)

Figure 8-Cross-sections of low-resolution meshes generated by (a) DesignModeler and (b) cfMesh, showing elements and refinement zones

resolutions, while the flow rates are correctly replicated between mesh types, it appears that the interface deformation is not. This suggests that on fine meshes not only is the absolute resolution important for determining the slag-metal interface distortion and breakup behaviour, but also the shape and local topology of the elements used in the mesh. The technique used to reconstruct the slag-metal interface surface and estimate its surface area also has a significant impact on the calculation of $\delta_{i}$ - the contour surface area method used here is known to be sensitive to mesh resolution and topology, and alternative methods more consistent with the underlying finite-volume formulation are currently being explored. Such aspects would need very careful consideration indeed should researchers wish to compare interface behaviour between different software platforms in the future.

\section{Sensitivity analysis}

Although models at low resolution are not fully meshindependent and should therefore never be used for applications
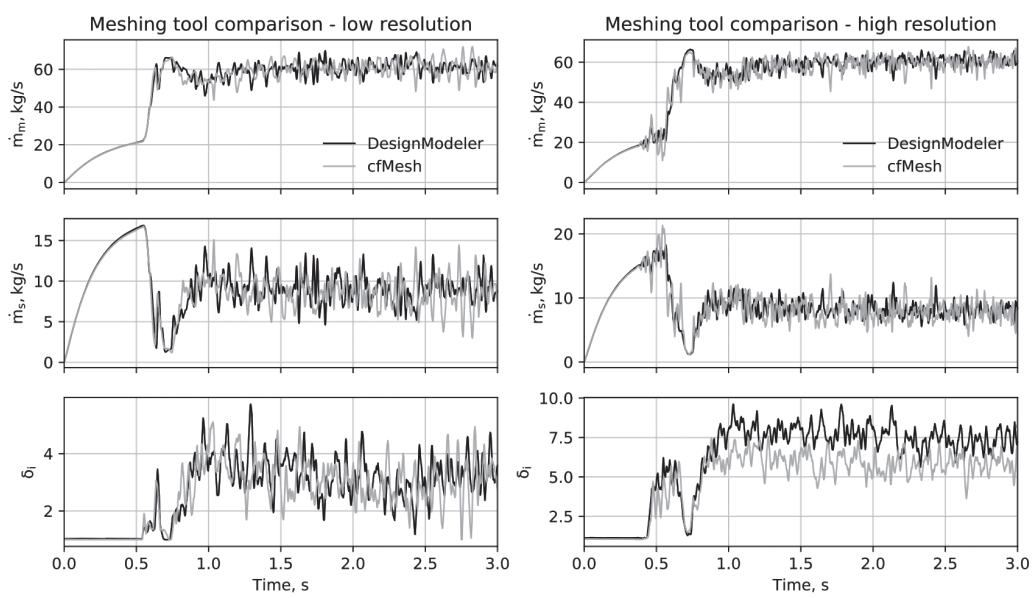

Figure 9-Comparison of time evolution of model results using different mesh generation algorithms 


\section{Phase effects in tap-hole flow - a computational modelling study}

requiring quantitative accuracy, their relative responses to changes in model parameters may still be expected to correctly indicate the sensitivities in the underlying problem physics. To achieve this for the ferromanganese tap-hole model, a large number of runs were performed using low-resolution DesignModeler meshes (tap-hole channel mesh element size $0.0025 \mathrm{~m}$ ) keeping all parameters from Table III fixed except one, which was raised and lowered by $25 \%$ of its value. The response of the three outputs of the model - the time-averaged slag and metal flow rates and interface deformation over the last $500 \mathrm{~ms}$ run time - to each parameter change was then used to estimate a sensitivity relative to the base case model outputs.

The complete sensitivity analysis was run for three major variations in the model - one per the default conditions in which the coke bed is located in the slag phase only, one in which the coke bed is allowed to extend into both slag and metal, and one in which the coke bed is entirely absent from the tap-hole entrance area.

\section{Coke bed in slag phase only}

For the default case in which the coke bed forms a porous medium in the slag phase only, the flow patterns inside the tap-hole channel are highly three-dimensional and complex. A selection of still frames from the model using base case parameters is shown in Figures 10a to 10c.

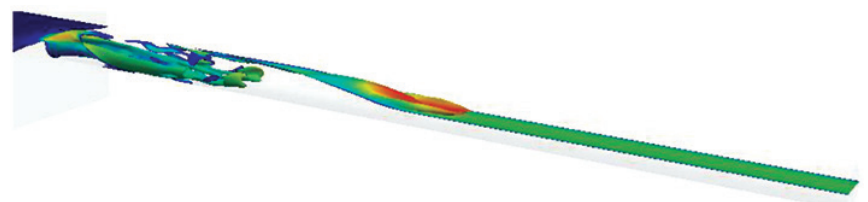

(a) $0.4 \mathrm{~s}$

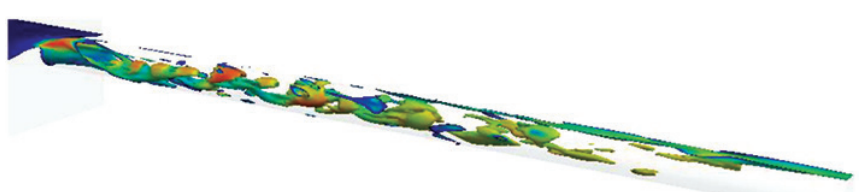

(b) $0.7 \mathrm{~s}$

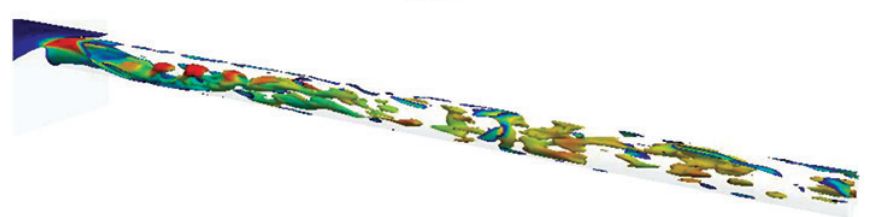

(c) $3.0 \mathrm{~s}$

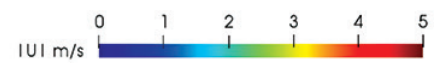

Figure 10-Evolution of slag-metal interface over time, base case with coke in slag phase only
The presence of the porous coke bed in the slag phase causes a partial obstruction to the material entering the tap-hole channel, and allows a higher flow rate of metal relative to slag to develop initially. This in turn causes the slag-metal interface to be forced upward as the metal enters beneath it, further restricting the slag flow. The end result is a metal-rich stream exiting the tap-hole, highly mixed with slag droplets due to the swirling flow and high shear rates that occur near to the entrance. Tapping mass flow rates for this case are $60.7 \mathrm{~kg} / \mathrm{s}$ metal and $9.3 \mathrm{~kg} / \mathrm{s} \mathrm{slag}$.

The sensitivity of the model to material properties for this case is shown in Figure 11. The model exhibits very strong sensitivity to the coke bed parameters. Increasing the coke bed porosity or coke particle diameter results in an increase in both the slag flow rate and the interface deformation, and a smaller decrease in the metal flow rate. Of the remaining parameters the metal density and slag viscosity have a significant effect, while metal viscosity and interfacial surface tension have virtually no impact on the model behaviour.

\section{Coke bed in slag and metal phases}

For the case in which the coke bed forms a porous medium around the tap-hole entrance in both the slag and metal phases, porous drag on the flow of both phases entering the tap-hole occurs. Still frames from this condition using base case model parameters are shown in Figures 12a to 12c.

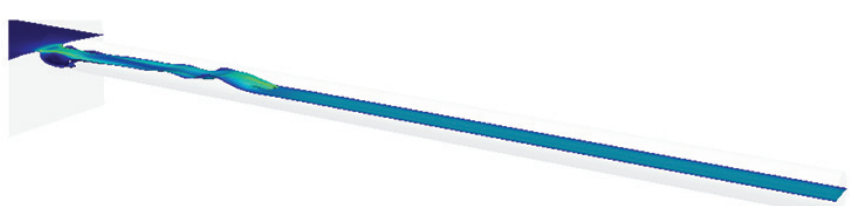

(a) $0.4 \mathrm{~s}$

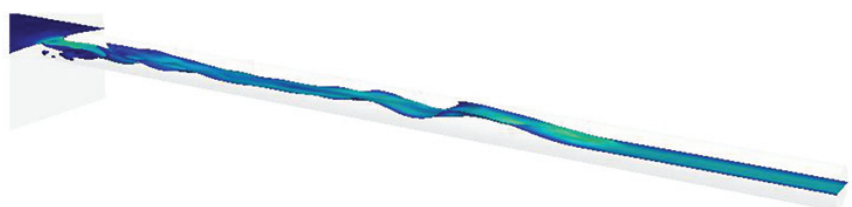

(b) $0.7 \mathrm{~s}$

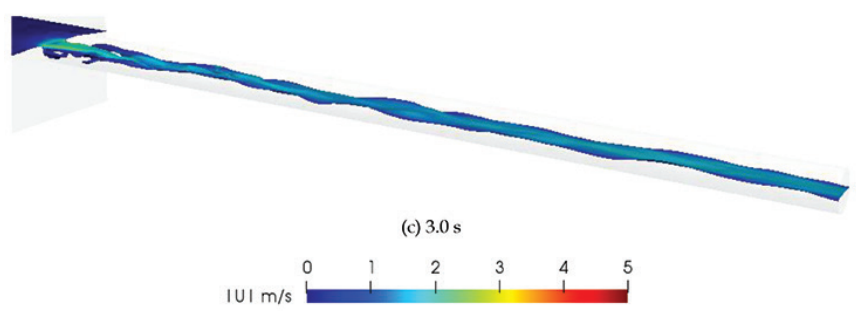

Figure 12-Evolution of slag-metal interface over time, base case with coke in slag and metal phases

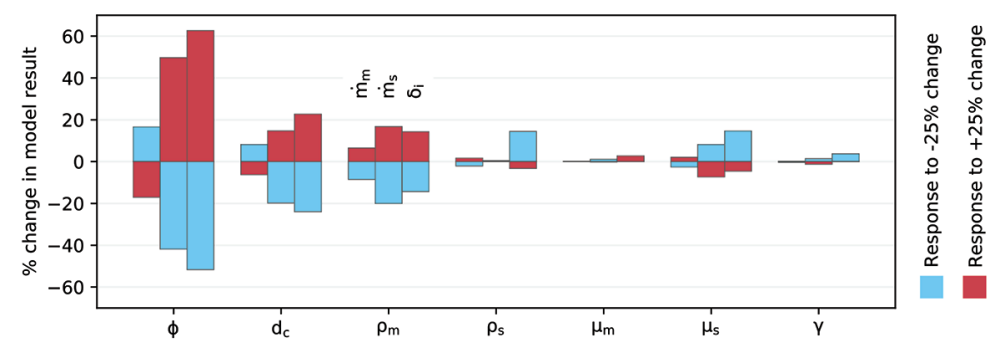

Figure 11-Positive and negative sensitivities of model results to material properties, coke in slag phase only 


\section{Phase effects in tap-hole flow - a computational modelling study}

It is immediately obvious when comparing to Figure 10 that the tapping velocities are significantly reduced when the coke bed obstructs both phases. While there is still some phase intermixing due to three-dimensional flow patterns near the channel entrance, this dissipates within a few tap-hole diameters and the slag and metal are well separated as they exit the tap-hole. Tapping mass flow rates for this case are $16.1 \mathrm{~kg} / \mathrm{s}$ metal and $7.1 \mathrm{~kg} / \mathrm{s} \mathrm{slag}$.

The sensitivity of the model to material properties for this case is shown in Figure 13. As before, the strongest effects on the model behaviour are as a result of changes to the coke bed parameters. In this case increasing the porosity or coke particle diameter causes both the slag and metal flow rates to increase, and to a lesser degree the interface deformation. Metal density has a significant impact on metal flow rate, and slag density has a significant impact on slag flow rate. Slag viscosity affects both flow rates to a smaller degree, and the model is again insensitive to metal viscosity or interfacial surface tension.

\section{No coke bed present}

For the case in which the coke bed is absent entirely from the tap-hole entrance region, only viscous and fluid acceleration forces limit the flow through the tap-hole. A series of still frames from this condition using base case model parameters is shown in Figures 14a to 14c.

Comparisons with Figures 10 and 12 show that when coke is absent from the tap-hole entrance region, the velocities in the tapping flow are considerably higher. The increased velocities lead to the formation of Kelvin-Helmholtz shear instabilities at the slag-metal interface, which results in partial breakup and intermixing of the two fluids. Tapping mass flow rates for this case were $35.8 \mathrm{~kg} / \mathrm{s}$ metal and $28.3 \mathrm{~kg} / \mathrm{s}$ slag.

The sensitivity of this model condition to material properties is shown in Figure 15. In this case, coke bed properties naturally do not affect the model. Of the remaining parameters, slag and metal densities cause the most significant changes in model outputs, affecting all three values. The fluid viscosities and interfacial surface tension have negligible effects on the flow rates, but are seen to change the interface deformation to a small degree.

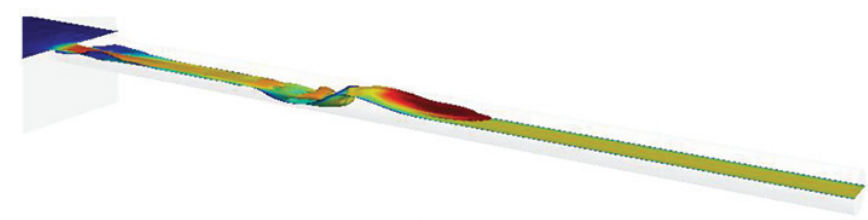

(a) $0.4 \mathrm{~s}$

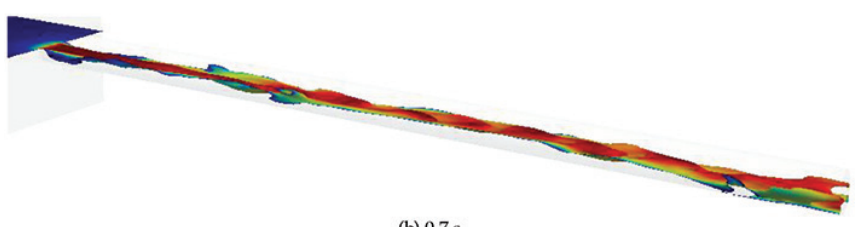

(b) $0.7 \mathrm{~s}$

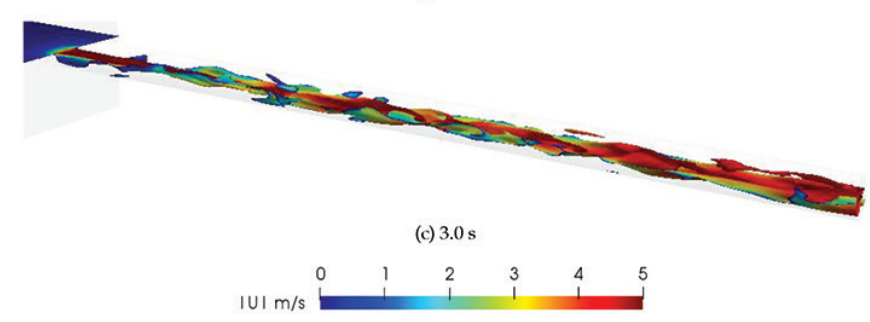

Figure 14 - Evolution of slag-metal interface over time, base case with no coke present

\section{Tap-hole wear effects}

While the base case model is representative of new ferromanganese tap-hole designs, tap-holes wear progressively throughout their lifetime and this can appreciably alter the geometry that the flow through the channel experiences at any given time. Tap-hole wear can vary greatly between designs, processes, and operating procedures (Nelson and Hundermark, 2016), and the way in which the geometry changes due to wear must therefore be assessed on a case-by-case basis.

In manganese furnaces, dig-out evidence (Steenkamp et al., 2014) suggests that the mechanism of wear is discrete failure of successive tapblock inserts as a result of chemical and thermal attack at the hot face inside the furnace. This results in a progressive shortening of the tap-hole combined with a widening of the entire channel as a result of tap-hole opening operations.

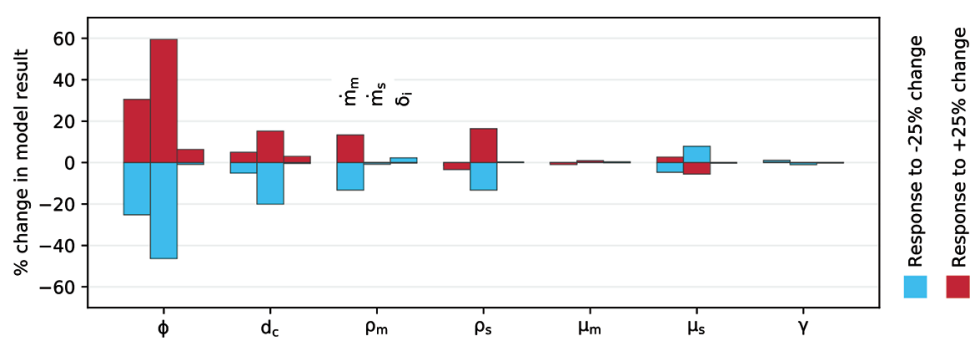

Figure 13-Positive and negative sensitivities of model results to material properties, coke in slag and metal phases

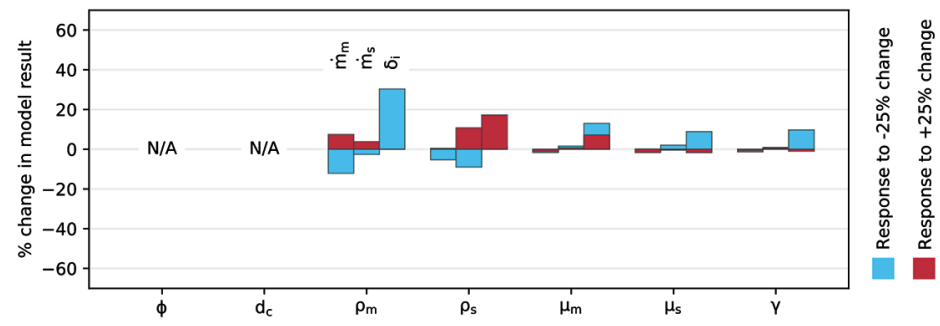

Figure 15-Positive and negative sensitivities of model results to material properties, no coke bed present 


\section{Phase effects in tap-hole flow - a computational modelling study}

The effect of this on the tapping flow behaviour was investigated by reducing $L$ and increasing $D$ in the low-resolution model geometry while keeping all other parameters in Table III fixed. The time-averaged results are shown in Figure 16.

Mass flow rates of both slag and metal increase approximately quadratically with increasing tap-hole diameter, indicating that the linear velocity of the tapping stream remains reasonably constant. In contrast, tap-hole length has relatively little effect on the flow rates; although a small decrease would be expected as the tap-hole increases in length, the difference between the 0.5 and $0.75 \mathrm{~m}$ cases is so small that it is overwhelmed by statistical noise generated by the dynamic fluctuations in the flow. This is in agreement with results from single-phase tap-hole flow models, which indicate that tap-hole flows are generally dominated by fluid momentum rather than viscous effects (Reynolds and Erwee, 2017).

The behaviour of the deformation of the slag-metal interface is more complex. The degree of interface deformation and mixing increases at larger diameters as the Reynolds number of the flow rises and the flow becomes more turbulent. There is also a strong decrease of $\delta_{i}$ with increasing tap-hole length, suggesting that most of the interface breakup occurs close to the tap-hole entrance - longer tap-holes therefore allow more time for slag and metal droplets to recombine and settle. Interface visualizations from worn tap-hole models are shown in Figure 17 and show the effect of shorter, wider tap-holes on the slag-metal interface.

In cases of extreme wear and very large tap-hole diameters it is possible that resistances to fluid flow in the furnace interior may also start to play a role in determining the tapping flow rates and patterns. This would be particularly significant when there are obstructions to the flow (low-porosity packed bed structures, sintered or solidified process material, broken electrodes) in the vicinity of the tap-hole entrance. Such effects are not considered here, but should be regarded as factors that may influence tapping behaviour, particularly under abnormal operating conditions.

\section{Operational parameters}

Changes in the hydrostatic pressure at the tap-hole inlet or interface position relative to the tap-hole centreline occur routinely during furnace operations. Pressures are affected by variations in charge composition and the heights of the slag, metal, and burden layers in the furnace. The slag-metal interface position typically changes over the duration of a single tap, with the interface starting above the tap-hole and dropping to level with, or even below it, as the furnace is emptied.

In order to study the effect these operational parameters have on the behaviour of the model, cases covering a range of tapping pressures and interface positions were run while holding all
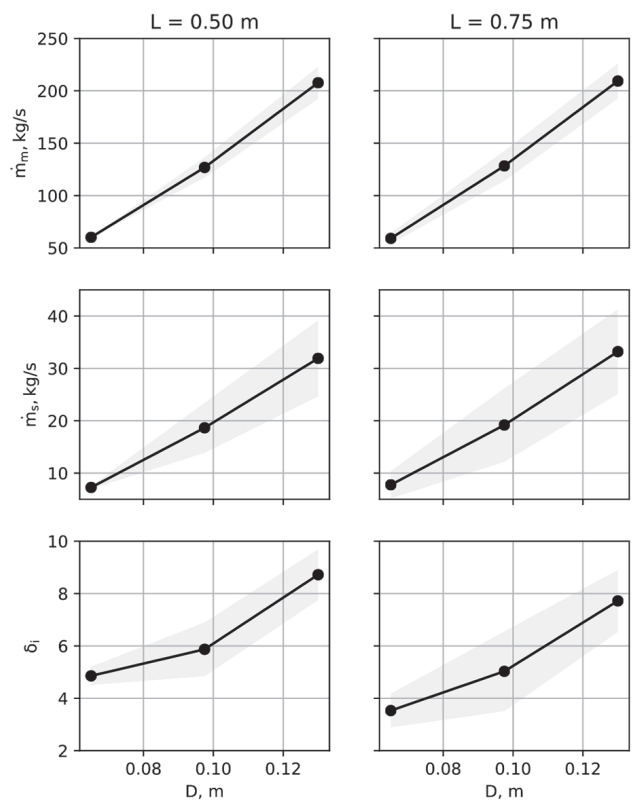

Figure 16-Changes in calculated variables with tap-hole length and diameter (solid line shows average for last $500 \mathrm{~ms}$ of model data, shaded region shows standard deviation)

other parameters at base case conditions, as per Table III. As the interfacial behaviour was of particular interest in these cases, the models used high-resolution computational meshes generated by DesignModeler (tap-hole channel element size $0.00125 \mathrm{~m}$ ).

\section{Tapping pressure}

$\Delta P$ was varied between 50 and $90 \mathrm{kPa}$, representing a likely operating range for a ferromanganese furnace. The effect of this change on the model outputs is shown in Figure 18.

Flow rates increase approximately as the square root of the hydrostatic pressure applied at the plenum boundaries, which is in general agreement with the principle of momentum-limited fluid flow in the tap-hole (Nelson and Hundermark, 2016; Reynolds and Erwee, 2017). Together with this increase in flow rates and linear velocities, the interface deformation increases gradually as the local shear forces in the fluid grow larger and cause more disruption and breakup of the slag-metal interface. The irregular behaviour of $\delta_{i}$ is related to the large degree of variability in this measure in the model results, as evidenced by the large standard deviation.

\section{Interface position between metal and slag}

Parameter $h_{i}$ was varied between $0.065 \mathrm{~m}$ above and below the tap-hole centerline (one tap-hole diameter in either direction). The response of the model to these changes is given in Figure 19.

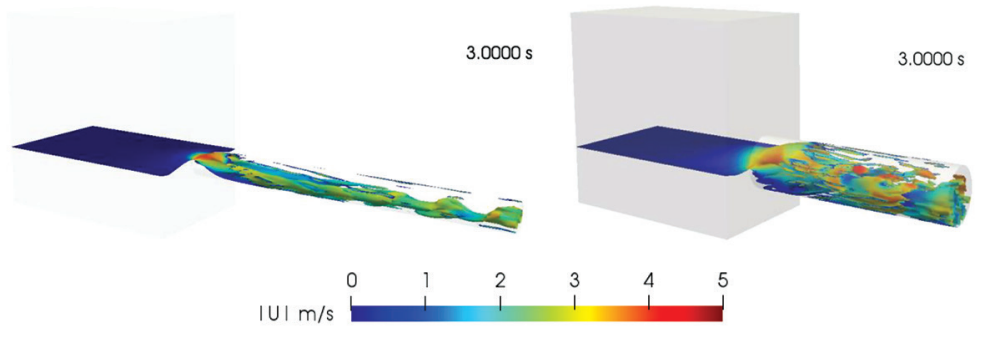

Figure 17-Slag-metal interfaces in worn tap-holes, (l) $L=0.75 \mathrm{~m}, D=0.065 \mathrm{~m}$ (r) $L=0.50 \mathrm{~m} D=0.13 \mathrm{~m}$ 


\section{Phase effects in tap-hole flow - a computational modelling study}
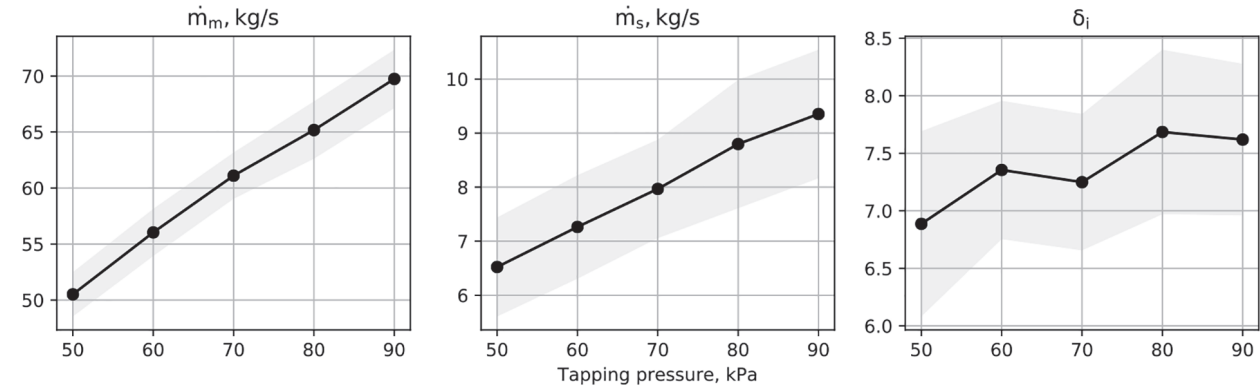

Figure 18-Changes in calculated variables with applied pressure (solid line shows average for last 500 ms of model data, shaded region shows standard deviation)
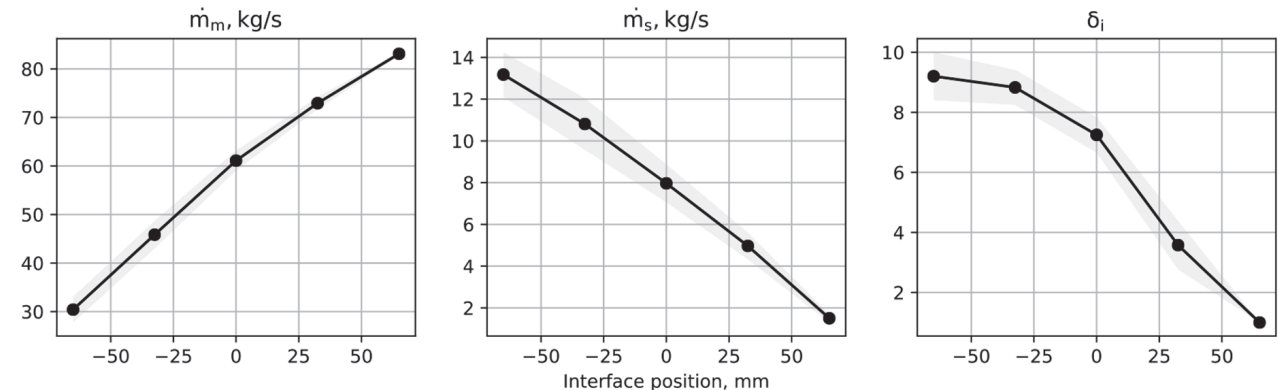

Figure 19-Changes in calculated variables with initial interface location relative to tap-hole centreline (solid line shows average for last 500 ms of model data, shaded region shows standard deviation)

As the slag-metal interface inside the furnace moves downward past the tap-hole entrance, as it would over the course of a normal tap, the flow rate of metal through the tapping channel drops substantially while at the same time the flow rate of slag increases gradually. This net reduction in tapping flow rate occurs as a result of the porous coke bed in the slag layer obstructing flow into the tap-hole more and more as the interface drops past the tap-hole entrance. Visualizations of the interface shape and structure at the end of the simulation for different values of $h_{i}$ are shown in Figure 20.

It is interesting to observe that the interface is drawn strongly toward the entrance as a result of the rapid flow acceleration into the tap-hole channel, even when it is well above or below the tap-hole centreline in the bulk interior of the furnace. This acceleration and change of direction causes a low-pressure region to develop at the tap-hole entrance, and this is sufficient to draw the interface into the channel from some distance above or below the tap-hole. Metal entrainment into the tap-hole is especially strong, and some metal may therefore be expected almost always to be drawn into the tapping stream. Interface deformation is also greatly increased as the slag-metal level in the furnace drops, predominantly as a result of the increasingly tortuous path the metal must take in order to enter the tap-hole. This causes additional shear stresses on the phase interface and results in more breakup and intermixing of slag and metal.

\section{Conclusions}

A computational model of isothermal fluid flow through a ferromanganese furnace tap-hole was successfully developed and implemented using open source tools. Multiphase flow and porous media effects were included in the model to account for the presence of slag, metal, and solid coke particles in and around the tap-hole. The model's numerical characteristics were tested and it was found that while fluid velocities and flow rates

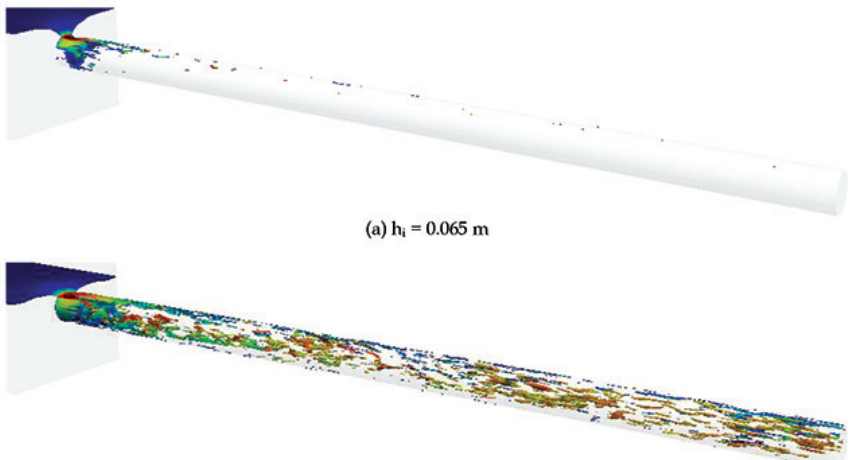

(b) $h_{i}=0.0325 \mathrm{~m}$

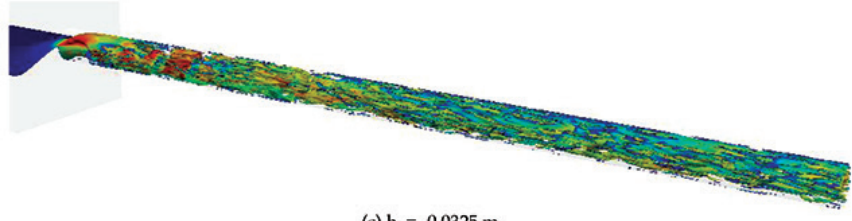

(c) $h_{i}=-0.0325 \mathrm{~m}$

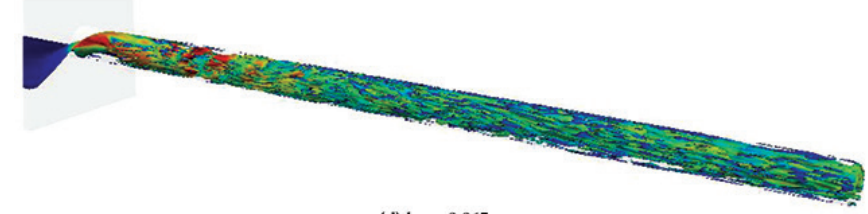

(d) $h_{\mathbf{i}}=-0.065 \mathrm{~m}$

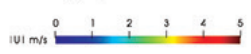

Figure 20-Slag-metal interfaces at end of simulation for different initial slag-metal levels

are predicted very consistently, effects related to the slag-metal interface are considerably more sensitive to the resolution and topology of the mesh used. 


\section{Phase effects in tap-hole flow - a computational modelling study}

The model was used to study the sensitivity of the tapping problem to various parameters related to the physical properties of the slag and metal fluids as well as the coke bed. It was found that in cases where a coke bed is present, the porosity of the bed and coke particle size have the greatest impact on tapping flow rates and slag-metal interface distortion. The spatial distribution of the coke bed in the vicinity of the tap-hole was also seen to have a dominating effect on the flow patterns - when coke was present in the slag phase only, more three-dimensional swirling flow and interface breakup at the tap-hole entrance was observed compared to the cases in which the coke was either absent or extended into both slag and metal phases.

The model was also applied to the effects of operational variables such as pressure and interface position variation during tapping, and tap-hole wear. Wider tapping channels typical of worn tap-holes were seen to significantly increase the flow rate of the tapping stream as well as the degree of slag-metal interface distortion, which is highest near to the tap-hole entrance. A greater hydrostatic pressure was observed to increase tapping flow rates in accordance with momentum-dominated rather than viscous-force-dominated fluid flow. The slag-metal interface in the furnace interior was also seen to be drawn down (or up) into the tapping channel from an appreciable distance above (or below) the tap-hole entrance; some mixing of slag and metal in the tapping stream is therefore likely to be inevitable throughout the duration of a tap.

This study is by no means exhaustive, and is intended to be a starting point for more focused discussions and investigations. Further work in this area is suggested in the following areas:

> Problem-specific validation of models against data from ferromanganese tapping operations

> Refinement of the understanding of the nature and location of the coke bed in the vicinity of the tap-hole

> Refinement of worn tap-hole geometries, including the possibility of a priori prediction using computational methods

> More extensive cross-verification of modelling results between meshing and software packages to determine appropriate settings for reliable comparisons

> Exploration of numerical interface compression schemes, interfacial mesh refinement algorithms, and sub-grid scale models to reach full mesh independence for reasonable computational cost

> Assessment of the risk/reward of including additional physics such as heat transfer, phase change, and thermochemical effects in computational models.

\section{Acknowledgements}

This paper is published by permission of Mintek. The assistance of our colleagues Dr Joalet Steenkamp, Dr Stein Tore Johansen, and others in discussing the problem statement and determining typical parameters for ferromanganese furnaces is gratefully acknowledged. Resources provided by the CSIR/Meraka Institute Centre for High Performance Computing were invaluable in the completion of this study.

\section{References}

ANSYS. 2018. Engineering simulation and 3D design software. https://www.ansys. com
Bale, C., Bélisle E., Chartrand, P., Decterov, S., Eriksson, G., Gheribi, A., Hack, K., Jung, I.-H., Kang, Y.-B., Melançon, J., Pelton, A., Petersen, S., Robelin, C., Sangster, J., Spencer, P. , and van Ende, M.-A. 2016. FactSage thermochemical software and databases 2010-2016. Calphad, vol. 54. pp. 35-53.

Barcza, N.A., Koursaris, A., See, J.B., and Gericke, W.A. 1979. The 'dig out' of a 75 MVA high-carbon ferromanganese electric smelting furnace. Proceedings of the 37th Electric Furnace Conference, Detroit, MI, 4-7 December 1979. American Institute of Mining, Metallurgical, and Petroleum Engineers, New York. pp. 19-33.

cfMesh. 2018. Creative Fields. https://cfmesh.com/

CHPC. 2018. Centre for High Performance Computing Lengau Cluster. https://www. chpc.ac.za/index.php/resources/lengau-cluster

Degel. R., Fröhling. C., Köneke. M., Hecker. E., Oterdoom. H., and van Niekerk. A. 2015. History and new milestones in submerged arc furnace technology for ferro alloy and silicon production. Proceedings of the Fourteenth International Ferro-Alloys Congress, INFACON XIV, Kyiv, Ukraine, 1-4 June 2015. pp. 7-16. https://www.pyrometallurgy.co.za/InfaconXIV/007-Degel.pdf

Kadкhodabeigi. M., Tvert, H., and Johansen, S.T. 2011. Modeling the tapping of silicon melt from the submerged arc furnaces. ISIJ International, vol. 51, no. 2. pp. 193-202.

Letsoalo, M. and SteEnKamp, J. 2017. Round robin standard composition: HCFeMn reference material. Proceedings of the 3rd SAIMM Young Professionals Conference, Pretoria, South Africa, 9-10 March 2017. Southern African Institute of Mining and Metallurgy, Johannesburg. pp. 355-357.

Mills, K.C. 2011. The estimation of slag properties. Short course given as part of SAIMM Pyrometallurgy 2011, Cradle of Humankind, South Africa, 6-9 March 2011. http://www.pyrometallurgy.co.za/KenMills/

Muller, J., Zietsman, J.H., and Pistorius, P.C. 2015. Modelling of manganese ferroalloy slag properties and flow during tapping. Metallurgical and Materials Transaction B, vol. 46B. pp. 2639-2651.

NELSON, L.R. and HundermaRk, R.J. 2016. The tap-hole - key to furnace performance. Journal of the Southern African Institute of Mining and Metallurgy, vol. 116, no. 5. pp. 465-490.

Olsen. S.E., TAngstad. M., and Lindstad T. 2007. Production of Manganese Ferroalloys. Tapir Academic Press, Trondheim, Norway.

OpenFOAM. 2018. The OpenFOAM Foundation.https://openfoam.org/

Oхтову, O.F., Heyns, J.A., and Suliman, R. 2013. A finite-volume solver for two-fluid flow in heterogeneous porous media based on OpenFOAM ${ }^{\circledR}$. Proceedings of the Open Source CFD International Conference 2013, Hamburg, Germany, 24-25 October 2013. pp. 1-12.

ParaView. 2018. ParaView. https://www.paraview.org/

REYNolds, Q.G. and ERwEE, M.W. 2017. Multiphase fluid flow modelling of furnace tap-holes. Proceedings of the 12th International Conference on CFD in Oil \& Gas, Metallurgical and Process Industries, Trondheim, Norway, 30 May - 1 June 2017. Sintef, Trondheim. pp. 521-530. http://www.opensourcecfd.com/ conference2013/proceedings

Steenkamp, J.D., Gous, J.P., Pistorius, P.C., Tangstad, M., and Zietsman, J.H. 2014. Wear analysis of a tap-hole from a SiMn production furnace. Proceedings of the SAIMM Furnace Tapping Conference, Muldersdrift, South Africa, 27-29 May 2014. Southern African Institute of Mining and Metallurgy, Johannesburg. pp. 51-62.

TAng, K. and TAngStAD, M. 2007. Modelling viscosities of ferromanganese slags. Proceedings of the Eleventh International Ferro-Alloys Congress INFACON XI, New Dehli, India, 18-21 February 2007. Indian Ferro Alloy Producers Association. pp. 344-357.

Yu, A.B., Zou, R.P., and STANDish, N. 1996. Modifying the linear packing model for predicting the porosity of nonspherical particle mixtures. Industrial \& Engineering Chemistry Research, vol. 35. pp. 3730-3741. 